\title{
Análise do desempenho econômico da região Centro-Oeste, Brasil, de 2002 a 2015
}

\section{Analysis of the economic performance of the Centro-Oeste region, Brazil, from 2002 to 2015}

Análisis del desempeño económico de la región Centro-Oeste, Brasil, de 2002 a 2015

Antônio Carlos Cantero Dorsa ${ }^{1}$ Michel Constantino ${ }^{2}$

${ }^{1}$ Mestrando em Desenvolvimento Local pela Universidade Católica Dom Bosco (UCDB), 2017. Pós-Graduação Lato Sensu MBA Executivo em Gestão Empresarial pela UCDB, 2012. Tem graduação em Administração Pública pela UCDB, 2009. E-mail: accdorsa@gmail.com, Orcid: http://orcid.org/0000-0002-2087-8772

${ }^{2}$ Doutor em Economia pela Universidade Católica de Brasília (UCB), mestre em Desenvolvimento Local pela UCDB e administrador. Professor nos Programas de Doutorado em Ciências Ambientais e Sustentabilidade Agropecuária e em Desenvolvimento Local. Pesquisador da área de Políticas Públicas Agroambientais, Economia Comportamental, Economia Regional e Econometria (Métodos Quantitativos). Pesquisador visitante do Instituto de Pesquisa Econômica e Aplicada (Ipea), Brasília, DF. Vice-coordenador do Programa de Mestrado e Doutorado em Desenvolvimento Local. Editor associado da Economic Analysis of Law Review. E-mail: michel@ucdb.br, Orcid: http://orcid.org/0000-0003-2570-0209 
Resumo: O processo de desenvolvimento econômico proporciona externalidades de formas distintas, dependendo da composição produtiva de cada território; nesse contexto, as diferenças regionais podem resultar em maior ou menor crescimento econômico. 0 presente artigo investigou o desempenho da região Centro-Oeste entre 2002-2015 e o comparou com a média nacional, utilizando análise quantitativa. Os indicadores utilizados para a análise foram o PIB, Gini, Exportação, Importação e Grau de Abertura Comercial (GAC). Os resultados mostraram que, no Gini, os estados de Mato Grosso e Mato Grosso do Sul, MS, foram acima da média nacional, e Goiás, GO, abaixo. A variável PIB seguiu a média nacional, enquanto as exportações apresentaram nível acima da média, e, nas importações, apenas MS foi superior. O GAC de GO e MS foi acima da média nacional, e o de MT, abaixo. Conforme a literatura, a presente pesquisa confirma que o Centro-Oeste continua acima da média nacional.

Palavras-chave: desigualdade; indicadores; economia; abertura comercial.

\begin{abstract}
The process of economic development provides externalities in different ways, depending on the productive composition of each territory; in this context, regional differences can result in greater or lesser economic growth. The present article investigated the performance of the Centro-Oeste region between 2002-2015 and compared it with the national average using quantitative analysis. The indicators used for the analysis were GDP, Gini, Exports, Imports, and Degree of Commercial Openness (GAC, in the Portuguese acronym). The results showed that, in the Gini, the states of Mato Grosso and Mato Grosso do Sul, MS, were above the national average, and Goiás, GO, below. The variable GDP followed the national average, while exports were above average, and, in imports, only MS was higher. The GAC of GO and MS was above the national average, and the one from MT, below. According to the literature, the present research confirms that the Centro-Oeste continues above the national average.
\end{abstract}

Keywords: inequality; indicators; economy; commercial opening.

Resumen: El proceso de desarrollo económico proporciona externalidades de formas distintas, dependiendo de la composición productiva de cada territorio; en este contexto, las diferencias regionales pueden resultar en mayor o menor crecimiento económico. El presente artículo investigó el desempeño de la región Centro-Oeste entre 2002-2015 y comparó con la media nacional, utilizando análisis cuantitativo. Los indicadores utilizados para el análisis fueron el PIB, Gini, Exportación, Importación y Grado de Apertura Comercial (GAC). Los resultados mostraron que, en el Gini, los estados de Mato Grosso y Mato Grosso do Sul, MS, fueron por encima del promedio nacional, y Goiás, GO, abajo. La variable PIB siguió la media nacional, mientras que las exportaciones presentaron un nivel por encima de la media, y, en las importaciones, sólo MS fue superior. El GAC de GO y MS fue por encima de la nacional, y el de MT, abajo. Conforme a la literatura, la presente investigación confirma que el Centro-Oeste continúa por encima de la media nacional.

Palabras clave: desigualdad; indicadores; economía; apertura comercial. 


\section{INTRODUÇÃO}

A redução da pobreza depende do crescimento econômico e da redução da desigualdade, sendo assim, o processo de desenvolvimento requer políticas públicas que melhorem o ambiente de negócios, fortaleça o capital humano e promova bens públicos como infraestrutura, segurança, saúde e, principalmente, bem-estar à sociedade.

O desempenho de uma região em países continentais como o Brasil varia muito, dependendo, entre outras coisas, da estrutura de incentivos, da logística, do empreendedorismo e da cultura local. O Banco Mundial (2000/2001) estimou o impacto do crescimento sobre a pobreza, por meio da elasticidade do índice de incidência de pobreza em relação à renda per capita, concluindo que, nos países com menor desigualdade inicial (coeficiente Gini em torno de 0,2), a elasticidade estimada é duas vezes superior à dos países com grande desigualdade (coeficiente Gini em torno de 0,6).

O Relatório de Desenvolvimento Humano mostrou que o Brasil, em 2010, encontrava-se na 85a posição no ranking global de Índice de Desenvolvimento Humano (IDH) (0,739), enquanto no ano 2000 o país estava em 73 ㅇ lugar $(0,757)$, ou seja, mesmo com a melhora de PIB per capita no período, houve uma queda no IDH de 4,25\%, a qual poderia ter sido mais grave caso não tivesse havido o aumento da renda por pessoa nesse período. Nesse sentido, esses indicadores apresentam os problemas sociais e econômicos que podem ser utilizados para aplicação de soluções e políticas públicas locais e regionais.

Nesse contexto, o presente estudo pretende investigar o desempenho da economia da região Centro-Oeste entre 2002-2015 e o comparar com a média nacional, utilizando como abordagem metodológica a análise quantitativa. Os indicadores utilizados para a pesquisa foram o Produto Interno Bruto (PIB), Índice de Gini (Gini), Exportação, Importação e Grau de Abertura Comercial (GAC).

Para o alcance do objetivo, o artigo foi dividido em cinco seções, incluindo esta introdução, a qual descreve sucintamente o contexto de estudo. A seção seguinte consiste numa revisão da literatura. A terceira seção apresenta a metodologia da pesquisa e os dados utilizados, seguidos da análise dos dados e das considerações finais. 


\section{REVISÃO DA LITERATURA}

De acordo com Resende e Magalhães (2013), a heterogeneidade regional brasileira é marcante e persistente ao longo das décadas, caracterizada pela própria extensão territorial, que, como afirma Barros (2011), seria capaz de gerar heterogeneidades, como se verifica em outros países de grandes dimensões territoriais.

No Brasil, as diversidades na formação histórica, social e climática contribuíram fortemente para a formação de tais diferenças entre as regiões (RESENDE; MAGALHÃES, 2013). Shankar e Shahm (2003), ao investigarem as disparidades dos PIBs per capita regionais para seis países de grandes dimensões territoriais no mundo, concluíram que o Brasil apresentava a terceira maior desigualdade regional, ficando atrás da Rússia e da China.

Indicador importante para tomada de decisões econômicas e na formulação de políticas públicas, o PIB, de acordo com Tremea (2011), pode ser calculado tanto pelo valor adicionado por setores econômicos, que deve ser equivalente à renda gerada, quanto pelo dispêndio da sociedade.

Diferenças de PIB entre as regiões brasileiras contrariam uma das principais previsões da teoria neoclássica de crescimento econômico, proposta inicialmente por Solow (1956), Swan (1956), Ramsey (1928), Cass (1965) e Koopmans (1965): a tendência progressiva de queda no tempo das diferenças dos valores relativos da renda per capita entre diferentes economias.

De acordo com Mankiw (2005), o PIB mede duas coisas importantes: o somatório da renda de todos os indivíduos do sistema econômico e o dispêndio total dos bens e serviços que são produzidos na economia. Portanto o Produto Interno Bruto de um país, estado ou região pode apresentar a situação da atividade produtiva e seus reflexos para a sociedade.

\subsection{Desigualdade regional}

As desigualdades regionais podem ser medidas por diversos instrumentos analíticos. Essas medidas ajudam a descrever a efetividade das políticas de redução da desigualdade e geram informações importantes para a análise e melhoria de políticas públicas. Além de analisarem a existência 
da convergência absoluta ou condicional da renda, vários instrumentos buscam compreender a dinâmica de distribuição da renda no espaço sob diversos aspectos (RESENDE; MAGALHÃES, 2013).

Os referidos autores supracitados analisaram a dinâmica do PIB per capita em quatro escalas territoriais nas regiões: Norte e Nordeste; Sudeste; Sul e Centro-Oeste. Os resultados mostraram que, quanto mais se reduz a escala territorial de agregação do PIB per capita, mais esse resultado se inverte. Enquanto, em 2008, o nível de dispersão do PIB per capita entre as mesorregiões do grupo Norte e Nordeste chegava em níveis similares ao "resto do país", entre 1999 e 2008, a dispersão do PIB per capita entre as microrregiões e do grupo "Norte e Nordeste", em vez de se reduzir, passou a aumentar e terminou o período em níveis bem maiores do que no "resto do país".

Afirmam Magalhães e Boueri (2009) que, enquanto a maior parte dos municípios do Sul, Sudeste e Centro-Oeste cresceu a altas taxas e se aglomerou nas classes de mais alta renda, a estagnação econômica ocorrida na maioria das regiões do Norte e do Nordeste as conduziu às mais baixas classes de renda e promoveu um esvaziamento da renda per capita média.

O Índice de Gini é um instrumento para medir o grau de concentração de renda em determinado grupo. Ele aponta a diferença, ou seja, a desigualdade entre os rendimentos dos mais pobres e dos mais ricos (INSTITUTO DE PESQUISA APLICADA [IPEA], 2004). Trata-se do índice de desigualdade de renda mais conhecido e de maior aplicação (NEDER, 2013). O Gini pode também ser usado para qualquer distribuição, como concentração de riqueza, de terra, entre outras (INSTITUTO DE PESQUISA E ESTRATÉGIA ECONÔMICA DO CEARÁ [IPECE], 2010). Para a análise do Índice de Gini, o número varia de zero a um, e alguns autores apresentam de zero a cem. Dessa forma, quanto mais o índice tende a zero, melhor será a distribuição de renda; quanto mais próximo de um, pior a distribuição de renda e a desigualdade (IPEA, 2004).

\subsection{Abertura comercial}

Com a diminuição das barreiras não tarifárias e a diminuição das tarifas a partir da década de 1990, a literatura defende que o Brasil passou por 
uma reforma de abertura comercial. De acordo com Rossi Junior e Ferreira (1999), os defensores da abertura comercial afirmam que a queda das barreiras comerciais aumentaria o acesso a insumos de melhor qualidade e, ao aumentar a competição, forçaria a indústria nacional a aprimorar seus produtos e seus métodos de produção. Os mesmos autores apresentaram resultados de que a produtividade brasileira, a partir de 1990 e até onde dispomos de dados (1997), passou a crescer a altas taxas, e não se pode rejeitar a hipótese de que a abertura comercial tenha exercido um efeito positivo sobre esse processo, ou seja, a diminuição das tarifas e o aumento das importações teriam levado a um maior crescimento da produtividade.

Conforme Krugman e Obstfeld (2010), a ocorrência da abertura comercial se dá pelo motivo de as capacidades produtivas das nações serem distintas e, para alcançarem vantagens competitivas e obterem ganhos no comércio externo, os países abrem mão de produzir tudo o que eles necessitam para manufaturar os produtos mais vantajosos economicamente. Segundo Canuto, Fleischhaker e Schellekens (2015), uma maior abertura comercial proporciona introdução mais profunda nas cadeias globais de valor, que resultariam em fechamentos de segmentos da cadeia de produção menos competitivos, os quais seriam substituídos por importações, eliminando as perdas da produção nacional ineficaz.

Nas palavras de Canuto, Fleischhaker e Schellekens (2015), o Brasil é uma economia muito fechada. Essa proporção era de apenas 27,6\% em 2013 - uma das piores do mundo. Afirmam ainda os autores que a abertura comercial do Brasil está muito abaixo dos parceiros do Brics, nos quais a proporção do comércio em relação ao PIB chegou a pelo menos $50 \%$ nos últimos anos.

A literatura específica indica que a vantagem competitiva do Brasil seria alavancada com a imersão nas cadeias de valor globais, que são evidentes nas indústrias associadas a recursos naturais; mas, com o provável acesso a insumos mais baratos, poderia também surgir em atividades específicas de produção ou serviços. Para isso, reformulações estratégicas das políticas públicas são fundamentais, numa natureza mais horizontal, possibilitando uma ruptura por completo nessa falta de abertura econômica brasileira (CANUTO; FLEISCHAKER; SCHELLEKENS, 2015). 


\section{PROCEDIMENTOS METODOLÓGICOS}

A presente pesquisa tem caráter exploratório e abordagem de análise quantitativa. O estudo utiliza séries temporais entre 2002 e 2015, com dados por Unidade da Federação (UF) de bases oficiais, como o Instituto Brasileiro de Geografia e Estatística (IBGE). Realizou-se inicialmente uma pesquisa documental para conhecer a abordagem teórica, as principais abordagens analíticas e as variáveis utilizadas na literatura específica.

A análise pretende, assim, comparar os resultados de Produto Interno Bruto, Índice de Gini, Importação, Exportação e Grau de Abertura Comercial para os estados de Goiás, Mato Grosso e Mato Grosso do Sul em relação à média brasileira. Em seguida, a matriz de correlação nos possibilita uma análise simultânea da associação entre as variáveis por meio dos coeficientes de Pearson, Spearman ou Kendall.

No nosso estudo, realizamos a correlação de Pearson, em que o coeficiente varia entre-1 e 1, onde (1) significa correlação perfeita positiva entre as variáveis, (-1) significa correlação perfeita negativa entre as variáveis, ou seja, se uma aumenta, a outra sempre diminui; e com (0) as variáveis não dependem linearmente uma da outra.

O estudo excluiu o Distrito Federal, por não ter como atividade principal o setor do agronegócio, sendo muito distinto dos demais estados da região Centro-Oeste.

\subsection{Dados}

\begin{tabular}{lll}
\hline \multicolumn{2}{c}{ Variáveis utilizadas } \\
\hline Variável & Descrição & Fonte \\
\hline PIB & Produto Interno Bruto & IBGE - Dados 2002-2015 \\
Gini & Índice de Gini & IBGE - Dados 2002-2015 \\
Exportação & Total Geral das Exportações & IBGE - Dados 2002-2015 \\
Importação & Total Geral das Importações & IBGE - Dados 2002-2015 \\
GAC & Grau de Abertura Comercial & IBGE - Dados 2002-2015
\end{tabular}


As variáveis utilizadas na pesquisa foram Produto Interno Bruto (PIB), Índice de Gini, Importação, Exportação e Grau de Abertura Comercial. O Instituto Brasileiro de Geografia e Estatística (IBGE) foi a fonte dos dados, em seu Sistema IBGE de Recuperação Automática (Sidra), e o período analisado foi entre os anos de 2002 e 2015.

\section{ANÁLISE DOS DADOS}

\subsection{Produto Interno Bruto}

Figura 1 - Variação do PIB (2002-2015)
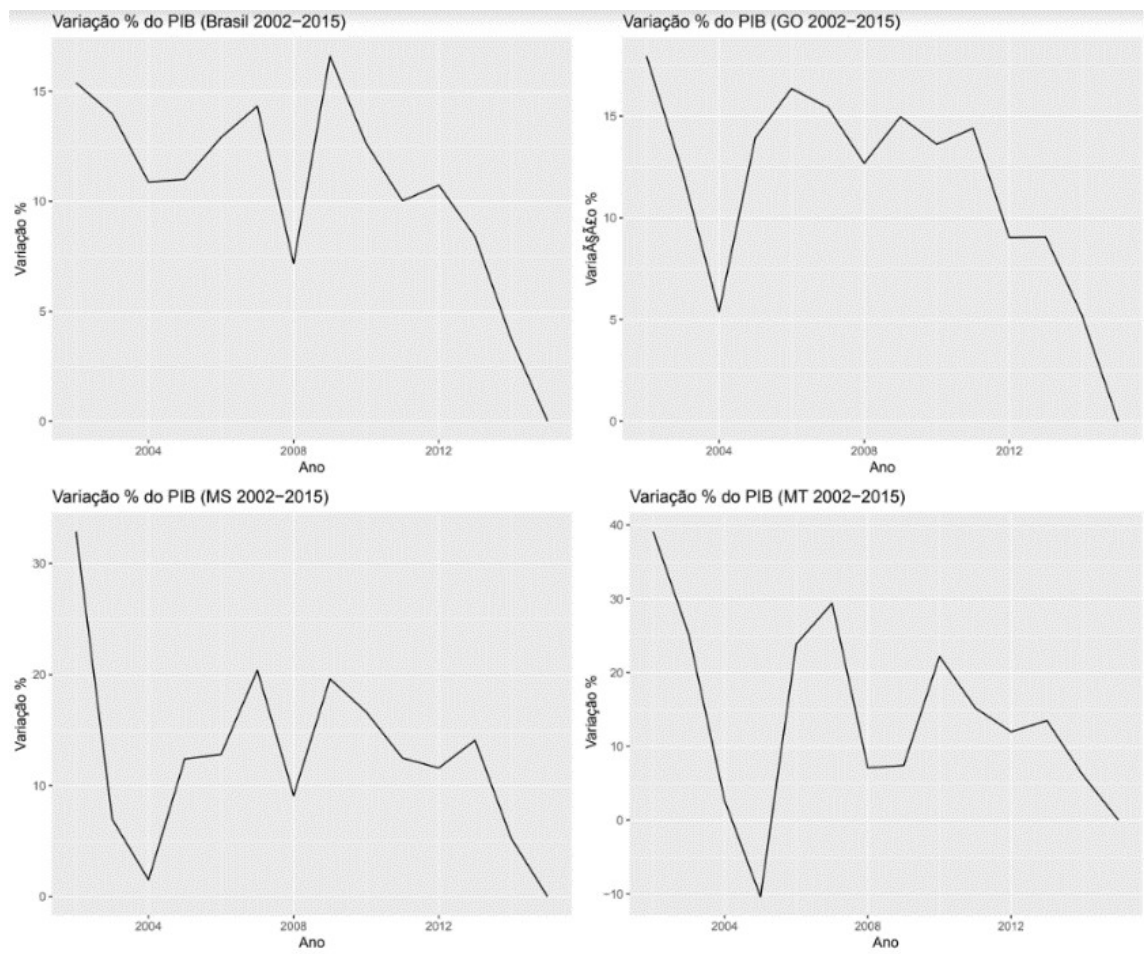

Fonte: Sidra-IBGE.

A variação percentual do PIB em MS em relação ao PIB nacional era, em 2002 , de 1,10\%, mantendo-se sempre num valor abaixo de 1,3\%, até 
2013, e 1,39\% em 2015. No Estado de MT, em relação ao PIB nacional, era de 1,29\% em 2002, mantendo-se sempre abaixo de 1,65\%, quando, em 2012, atingiu esse valor, e 1,79\% em 2015. O estado de Goiás tem um valor superior em relação ao valor nacional do que os dois primeiros estados, mantendo-se de 2002 a 2008 numa média de 2,6\% do valor nacional, 2,84\% em 2013 e 2,90\% em 2015.

As médias entre as variações percentuais nesse período, entre a nacional e os estados da região Centro-Oeste, foram muito próximas entre si. A do Brasil foi de 11\%, Mato Grosso do Sul, 12,48\%, Mato Grosso, 13,48\%, e Goiás, 13,61\%, mostrando, assim, que todos os estados da região CentroOeste tiveram índices acima da média nacional.

De acordo com Cavalcante e De Negri (2014), citados por Constantino, Pegorare e Costa (2016), o Brasil passou por um ciclo econômico e de inclusão social no início de década de 2000 até o ápice da crise financeira mundial em 2008. Mesmo após 2008, com exceção de 2010, as taxas de crescimento do Produto Interno Bruto (PIB) foram menores que as do período anterior e em relação a ganhos em renda per capita e à redução da desigualdade não se observaram retrocessos.

Ainda segundo os mesmos autores, alguns fatores contribuíram para esse ciclo de crescimento e inclusão social: políticas de redistribuição de renda, valorização do salário mínimo, expansão de crédito e acessibilidade da população ao mercado de trabalho, de maneira que o consumo foi impulsionado atrelado a um cenário externo de crescimento acelerado, valorando, assim, as commodities exportadas pelo Brasil.

O estado de Mato Grosso, segundo Grasel et al. (2008), pode ter uma questão preocupante com o passar dos anos, que é a forte dependência relativa a poucos produtos, em especial a soja, voltado para o mercado externo, colocando o estado numa situação frágil diante dessas instabilidades do mercado de commodities.

Constantino, Pegorare e Costa (2016) afirmam que o PIB de Mato Grosso do Sul apresentou, nos últimos anos, uma tendência de alta, acompanhando o PIB nacional, e que esse comportamento cria expectativa de melhoria de bem-estar na população, mas que esse crescimento nem sempre é distribuído homogeneamente entre a população. 
Guilhoto et al. (2007) afirmam que o PIB do agronegócio do Centro-Oeste é muito aquém com o volume de grãos produzidos e a grandeza do seu rebanho, sendo que, em 2004, apenas 12\% do PIB do agronegócio do país era de responsabilidade dessa região. Uma das explicações é de que a maior parte das indústrias (montante ou jusante) localiza-se no Sul e no Sudeste, e uma grande parcela da sua produção é destinada in natura diretamente para o mercado externo (exportação).

Na pecuária, ressaltam os autores, cresceu o número de frigoríficos nos últimos anos e parcela significativa deles está localizada no estado de São Paulo. A característica central do agronegócio da região Centro-Oeste se baseia na grande propriedade e na plantation com foco principal na exportação. Os estados dessa região possuem tecnologia de última geração e insumos de primeira linha.

A maior parte do PIB do setor concentra-se na produção de grãos, que é responsável por mais de $50 \%$ do PIB de Mato Grosso e de Goiás. Em MS, o PIB do agronegócio está concentrado na pecuária bovina, maior rebanho do país, e Goiás ainda tem destaque com a sua bacia leiteira.

Diniz (2006) destaca que a cultura da cana tem crescido nos últimos anos devido à expansão na região das usinas de açúcar e álcool.

No Relatório de Pesquisa da TRU (Tabela de Recursos e Usos) e Construção da Matriz Insumo-Produto (2008) de Campo Grande, MS, destacou-se que, quando se compara a participação do setor agropecuário em relação ao PIB no Estado de Mato Grosso do Sul, este apresenta uma taxa superior à brasileira. Assim, mostra-se a importância desse setor para a economia do estado, sendo que o produto bovino representa para a composição do PIB agropecuário, aproximadamente, 78\%. 


\section{2 Índice de Gini}

Figura 2 - Variação do Índice de Gini (2002-2015)
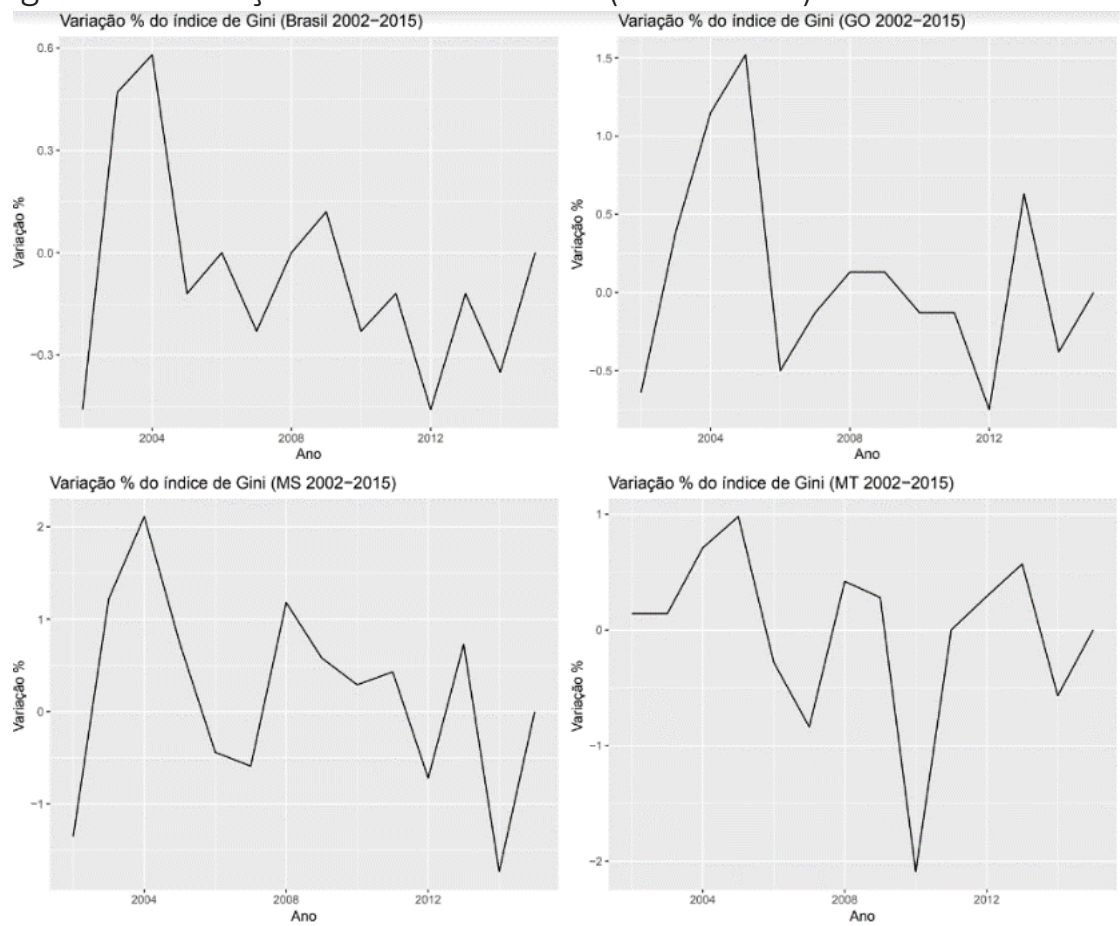

Fonte: Sidra-IBGE.

A média entre as variações percentuais nesse período, entre a nacional e os estados da região Centro-Oeste, foi: Brasil,-12\%; Goiás,-13\% (1\% abaixo da nacional); Mato Grosso, 14\% (26\% acima da nacional); e Mato Grosso do Sul reduziu sua desigualdade de renda em 43\% (57\% acima da média nacional).

O estado de Mato Grosso, conforme Grasel et al. (2008), tem características de estrutura fundiária, e isso pode impor limites à eficácia social de seu crescimento. É uma estrutura fortemente concentrada, com mais de 40\% de seus estabelecimentos agropecuários com mais de 100 ha, o que equivale a quase $97 \%$ de sua área total, sendo que, desses, quase $89 \%$ são de estabelecimentos com mais de 500 hectares.

Uma característica da agricultura brasileira na região Centro-Oeste é a desigualdade de rendimentos do trabalho entre as pessoas, e em 2002, 
segundo Corrêa e Figueiredo (2006), os patamares estavam elevados, o que indicava que o forte crescimento da agropecuária não equacionou a forte concentração de rendimentos que caracterizava o setor. Apesar de os rendimentos médios na região mostrarem-se superiores à média do país, as autoras ressaltam ainda que se constatou forte assimetria positiva na distribuição de rendimentos do trabalho entre as pessoas na agricultura e elevada intensidade de pobreza na região.

De acordo com Cacciamali e Camilo (2008), em seu estudo sobre a queda da desigualdade na distribuição domiciliar de renda no Brasil no início do século XXI, foi analisado o grau de desigualdade da distribuição da renda do trabalho no subperíodo considerado (2001 a 2004) e verificou-se a redução do Índice de Gini nacional de 0,56 para 0,54. Entretanto, mesmo com essa redução, a desigualdade na distribuição da renda no Brasil se manteve muito elevada diante dos padrões internacionais, inclusive quando cotejada com economias de nível de renda por pessoa similar. Esse grau de concentração era alto nas regiões Nordeste e Centro-Oeste, porém estas superaram o grau nacional, atingindo coeficientes de 0,59 e 0,58 em 2004, respectivamente. As maiores quedas relativas no grau de desigualdade, entre 2001 e 2004, ocorrem nas regiões Sul, Norte (urbano) e Nordeste, enquanto, nesse último ano, os menores coeficientes de desigualdade ocorrem nas regiões Sudeste e Sul (0,51 e 0,52, respectivamente), o que indicou à época uma maior organização institucional e melhores oportunidades de emprego, trabalho e renda. 


\subsection{Exportação e importação}

Figura 3 - Variação das Exportações (2002-2015)
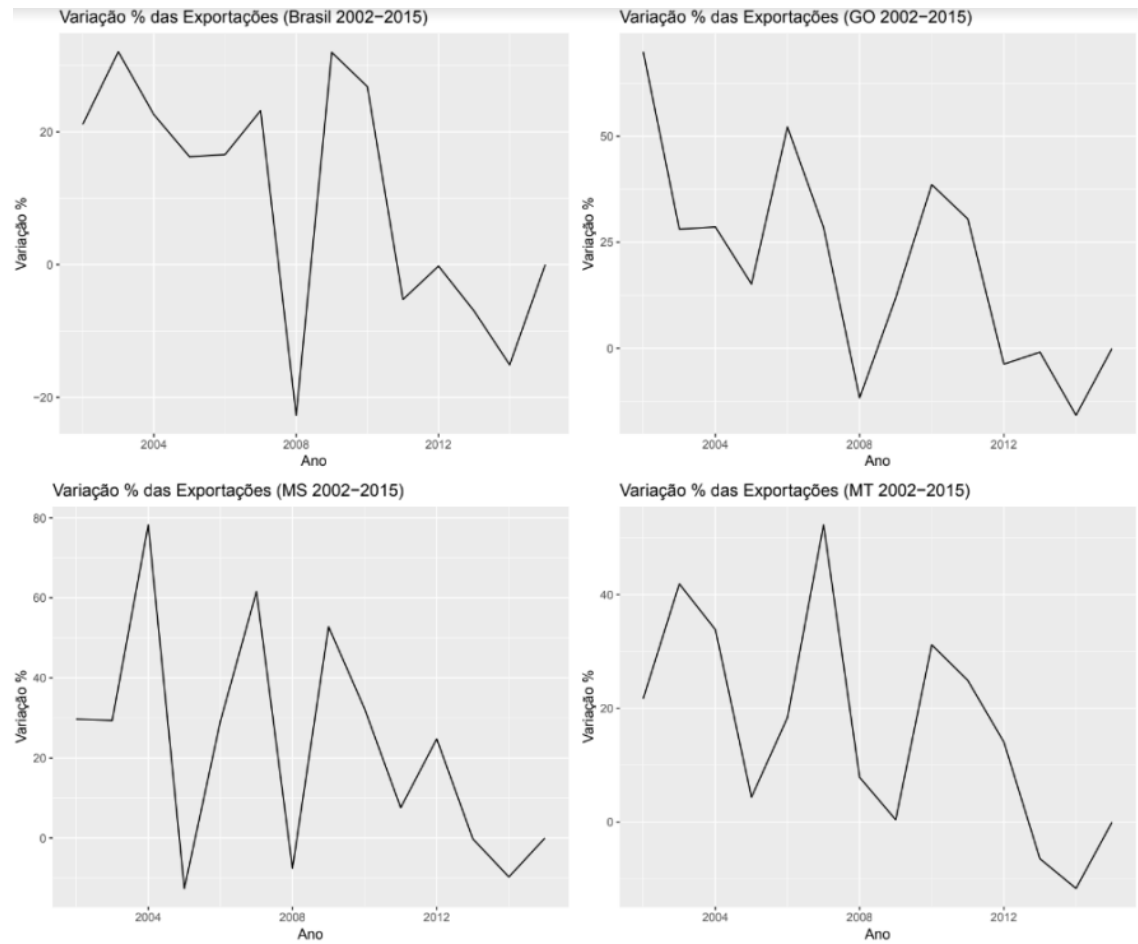

Fonte: Sidra-IBGE.

Nas exportações, o estado de Mato Grosso do Sul sempre apresentou índices abaixo de 1\% em relação ao valor total nacional dos anos de 2002 a 2007, 1,47\% em 2010, 2,33\% em 2014 e 2,48\% em 2015. Em contraste, Mato Grosso sempre teve os melhores índices da região, em que, nos anos de 2002 a 2007, representava 3\% do valor nacional, 4,19\% em 2010, 6,53\% em 2013 e 6,84\% em 2015. O Estado de Goiás representava, de 2002 a 2008, uma média superior a 1,5\% em relação ao total geral brasileiro, 2,36\% em 2009, 2\% em 2010 e 2011, e 3\% de 2012 a 2015.

A média entre as variações percentuais nesse período, entre a nacional e os estados da região Centro-Oeste, foi: Brasil, 16,58\%; Goiás 28,09\% (11,51\% acima da nacional); Mato Grosso, 18,4\% (1,82\% acima da nacional); e Mato Grosso do Sul, 29,16\% (12,58\% acima da média nacional). 
No Relatório de pesquisa: elaboração da TRU e construção da matriz insumo-produto (FAGUNDES, 2008), foi constatado que, entre os anos de 2008 e 2012, a produção de cana-de-açúcar cresceu 113,8\%, enquanto a de milho aumentou em 71\%; entretanto nenhuma cultura conseguiu valores tão altos como o milho, que ampliou as exportações em 719\%.

A agricultura, com valores mais aquém, tem a sua grande importância na região. A bovinocultura aumentou em $26,2 \%$ a quantidade de animais, e a suinocultura, em 46\%, ficando os aumentos nas exportações desses produtos semelhantes ao aumento na quantidade de animais: $21,5 \%$ para a bovinocultura e 44,7\% para os suínos.

Silva, Lima e Batista (2012), em seu estudo sobre a importância da soja para o agronegócio brasileiro, afirmam que, analisando as exportações, os resultados indicam que a soja compõe um produto bastante expressivo da exportação brasileira e bem relevante na criação de divisas para o país. Isso é explicado pela sua elevada produtividade, que, ajudada pelos baixos custos de produção, fez com que o Brasil entrasse no mercado internacional com o produto (a soja) a preços competitivos.

Segundo Kawamoto, Santana e Fonseca (2013), o seu trabalho foi justificado por ter dado foco na análise da importância da indústria de transformação sobre os totais dos valores importados e exportados. O destaque nas exportações é a indústria de transformação, representando $77 \%$ do valor exportado no período (2003/2010); em seguida, a extrativista, com 14\% do total. Nas exportações, os destaques são produtos alimentícios, metalurgia, veículos e produtos químicos, com participações médias nos valores totais do período de $23 \%, 13,4 \%, 12,3 \%$ e $6,7 \%$, respectivamente. 
Figura 4 - Variação das Importações (2002-2015)
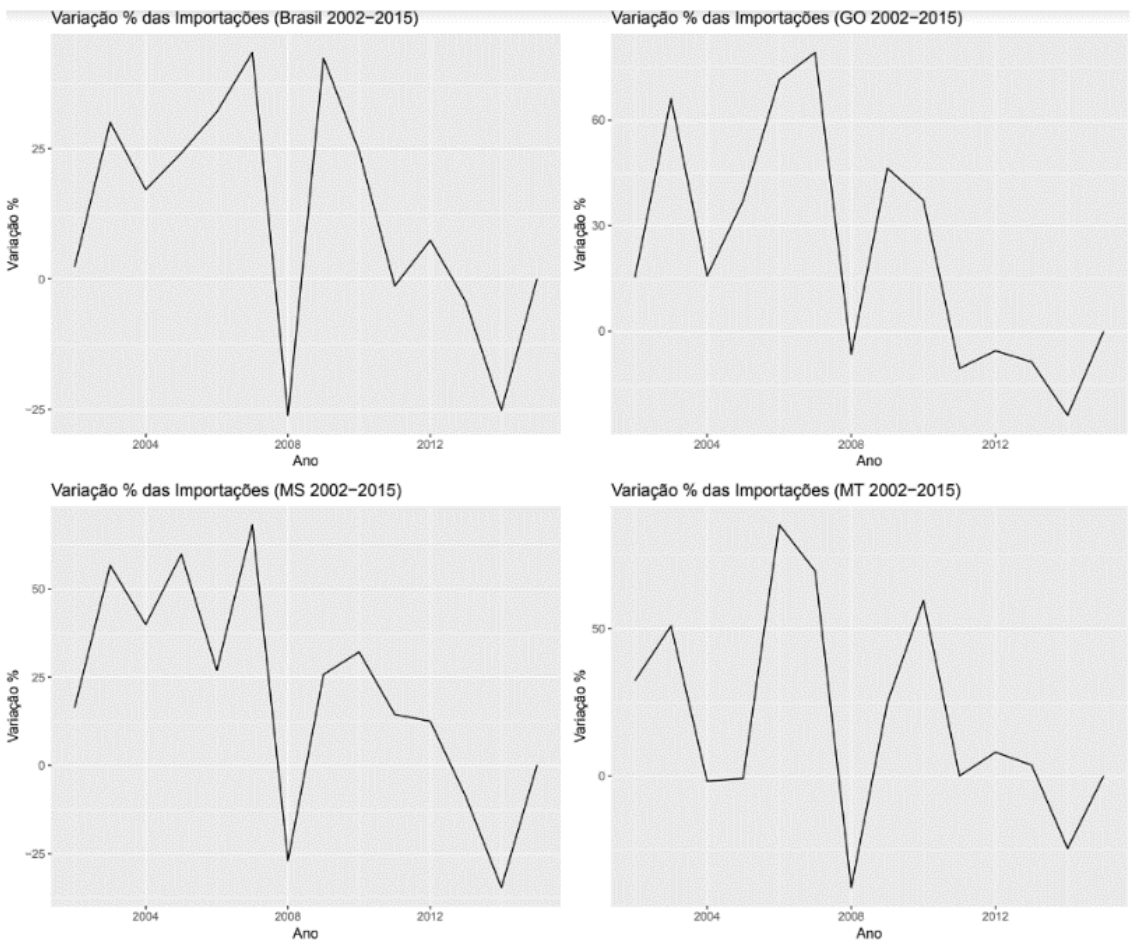

Fonte: Sidra-IBGE.

O estado de MS, de 2002 a 2005, importou, em média, 1\% do valor total nacional, representando 1,89\% em 2006, 1,86\% em 2010, 2,4\% em 2013 e 2\%, em média, em 2014 e 2015. O estado de MT representou, nos anos de 2002 a 2010, 0,5\% de média em relação ao total nacional, elevando a 0,7\%, de 2011 a 2015, sua representatividade. O estado goiano representou uma média abaixo de 1\% até 2006; 1,5\% de média em 2007 e 2008; e 2\% de média de 2009 a 2015.

A média entre as variações percentuais nesse período, entre a nacional e os estados da região Centro-Oeste, foi: Brasil, 17,13\%; Goiás, 15,71\% (1,42\% abaixo da nacional); Mato Grosso, 8,02\% (9,11\% abaixo da nacional); e Mato Grosso do Sul, 25,74\% (8,61\% acima da média nacional).

Santos et al. (2009) apontam o crescimento médio das importações brasileiras de 9,73\%, de 1993 a 2006. A região Sudeste, possuidora da maior 
demanda por importações, apresentou o menor crescimento médio do período considerado. O maior crescimento médio da demanda de importações foi o da região Centro-Oeste, com 20,18\%, e, surpreendentemente, o crescimento das importações do estado de Mato Grosso do Sul foi o maior de todos, mais de 2.100\% entre 1999 e 2006, ficando colocado entre os principais estados brasileiros importadores.

Segundo Kawamoto, Santana e Fonseca (2013), entre os produtos importados, os da indústria de transformação têm maior destaque, representando, em média, $85 \%$ do valor total das importações. Na sequência, encontram-se os produtos da indústria extrativa, representando, em média, $13 \%$ do total importado entre 2003 e 2010. Entre os produtos de transformação citados acima, na importação, nesse período avaliado, estão produtos químicos, de informática, máquinas, equipamentos e veículos, com participações médias nos valores totais do período de 19,5\%, 17\%, 12,2\% e $10 \%$, respectivamente.

\subsection{Grau de abertura comercial}

A equação para se calcular o GAC é:

$$
G A C(t)=\frac{X(t)+M(t)}{\operatorname{PIB}(t)}
$$

$\mathrm{GAC}(\mathrm{t})$ = é o grau de abertura comercial da UF ao longo do tempo; $X(t)$ é o valor das exportações totais do estado no período $t, M(t)$ é o valor das importações totais do Estado no período t e PIB é o Produto Interno Bruto total do Estado no período t. 
Figura 5- Variação do GAC (2002-2015)
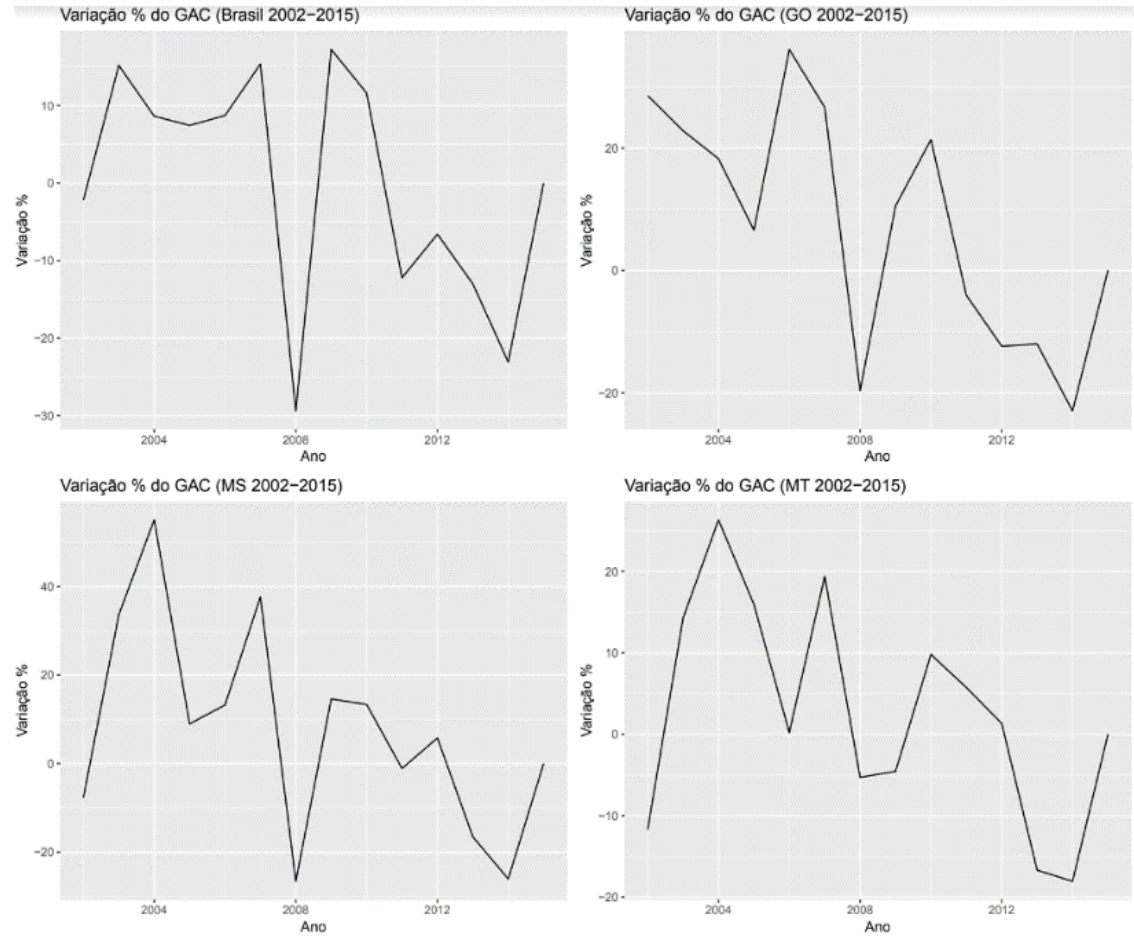

Fonte: Sidra-IBGE.

A média entre as variações percentuais nesse período, entre a nacional e os estados da região Centro-Oeste, foi: Brasil, 7,44\%; Goiás, 10,54\% (3,1\% acima da nacional); Mato Grosso, 1,32\% (6,12\% abaixo da nacional); e Mato Grosso do Sul, 8,96\% (1,52\% acima da média nacional).

As variações no Grau de Abertura brasileiro e nos estados da região Centro-Oeste são pequenas e, em muitos dos anos, são variações negativas - como em 2008, ápice da queda de abertura comercial -, mantendo-se baixas em todo o período medido.

O comércio é moderadamente importante para a economia brasileira segundo a The Heritage Foundation (2018), sendo que as barreiras não tarifárias impedem o comércio, e a abertura do governo ao investimento estrangeiro está abaixo da média. Os mercados bancários e de capital são diversificados e crescem, mas o envolvimento do Estado nos mercados de 
crédito tem se expandido constantemente, e os bancos públicos respondem por $50 \%$ dos empréstimos ao setor privado. O Brasil é a 153a economia mais livre no índice de 2018.

Silva, Lima e Batista (2012) destacam que a demanda de soja brasileira vem se elevando nos últimos anos e que cinco fatores são os responsáveis por essa elevação no mundo e, por conseguinte, no Brasil: I - Renda per capita mais alta; II - Uma maior distribuição do produto foi acompanhada pelo crescimento econômico; III - Crescimento econômico da China e da Índia; IV - Abertura econômica de países que eram, até então, "fechados" comercialmente; $V$ - Facilitação do investimento em empresas dos mais diferentes países.

\subsection{PIB em relação à desigualdade}

Figura 6 - Correlação PIB x Desigualdade (2002-2015)
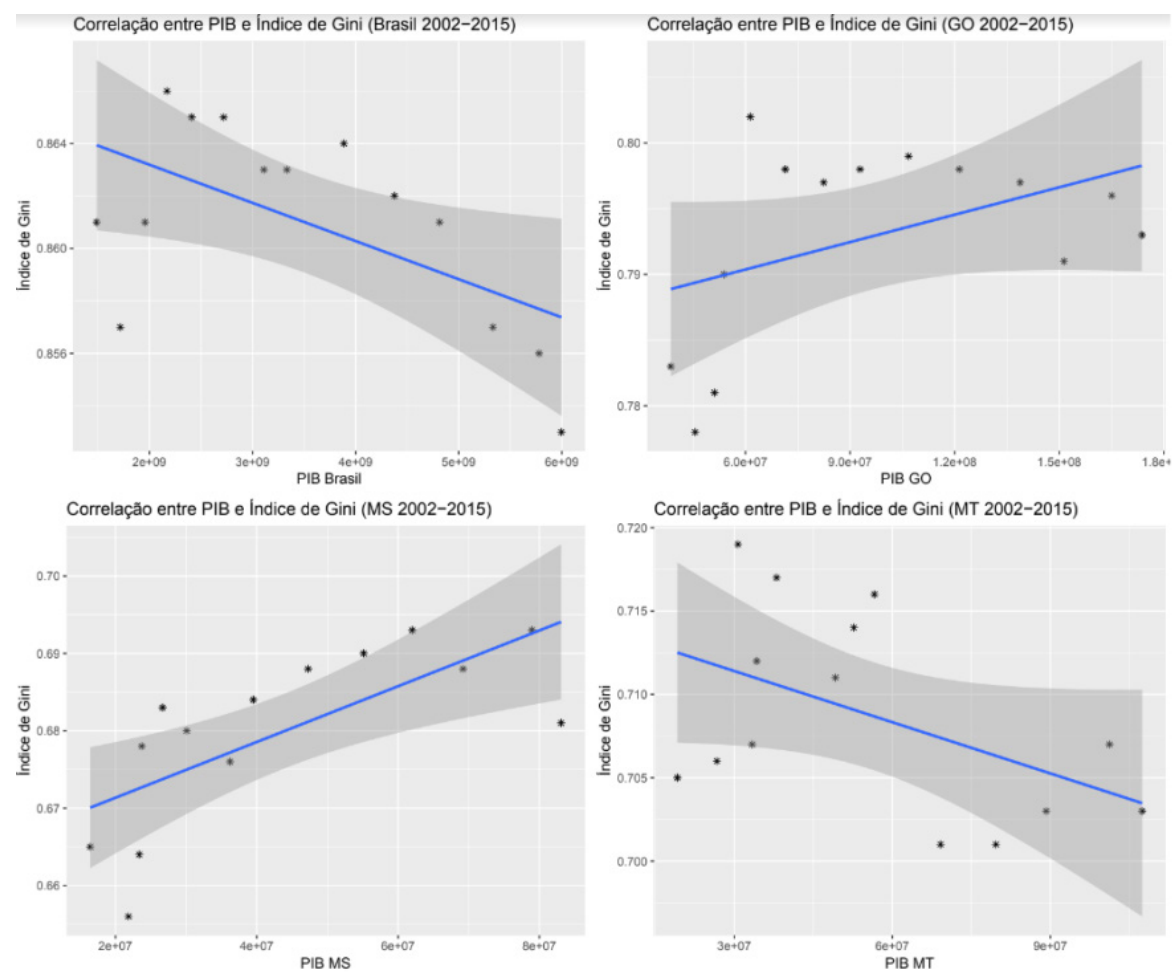

Fonte: Sidra-IBGE. 
O índice nacional e o índice do estado de Mato Grosso mostram que o aumento do PIB pode gerar uma diminuição na desigualdade de renda da população, sendo nos estados de Goiás e Mato Grosso do Sul o contrário, ou seja, um aumento do PIB pode gerar mais desigualdade de renda na região.

Em seu estudo, Marques (2009), por meio da matriz de correlação e do teste de Spearman, verificou que existe uma correlação inversa, significativa, entre o crescimento econômico e o grau de desigualdade no Rio Grande do Sul. Constatou, assim, que as regiões com grau menor de desigualdade podem crescer a taxas mais elevadas.

\subsection{GAC em relação à desigualdade}

Figura 7 - GAC x Desigualdade (2002-2015)

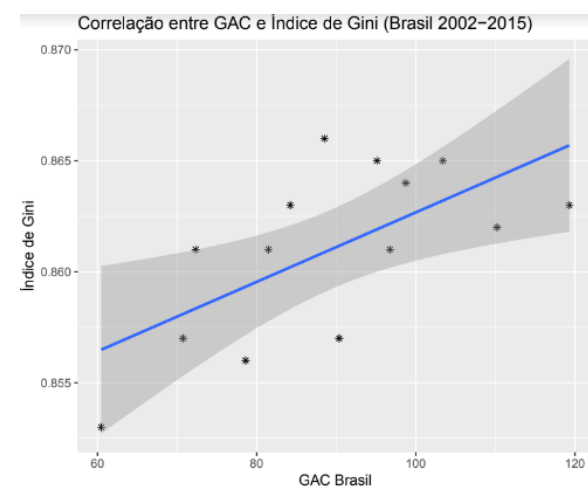

Correlação entre GAC e Índice de Gini (MS 2002-2015)

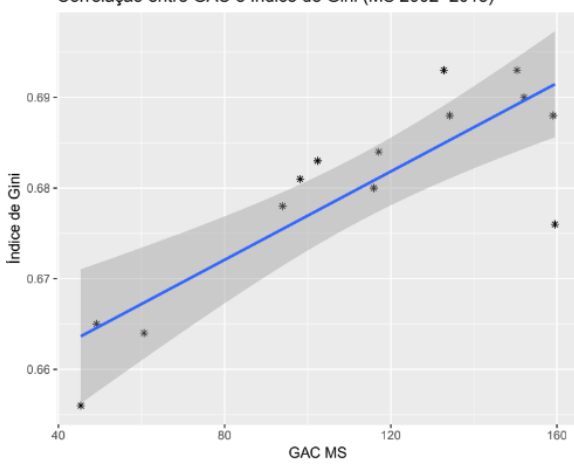

Fonte: Sidra-IBGE.

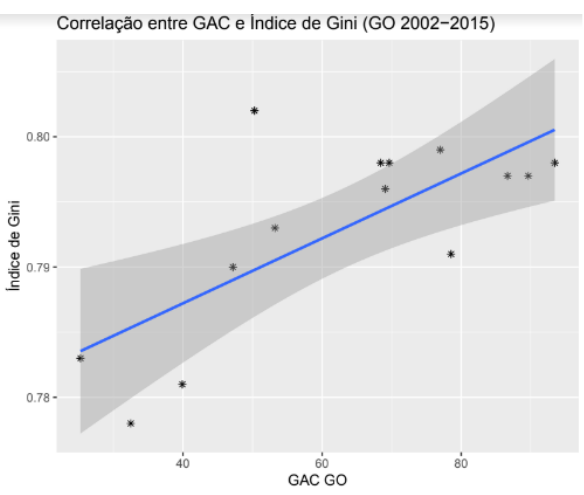

Correlação entre GAC e Índice de Gini (MT 2002-2015)

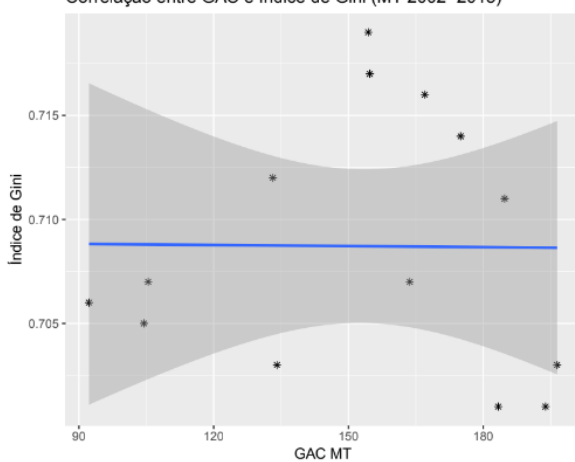


Por ser um dos países mais fechados economicamente no mundo, o Grau de Abertura Comercial brasileiro em relação à desigualdade de renda não representa uma relação parecida com países de maior abertura comercial, não nos mostrando impacto interessante nessa relação; e, no geral, mostra que uma maior abertura comercial pode aumentar a desigualdade de renda, exceto no estado de Mato Grosso, que nem sequer alterou para mais ou para menos.

\subsection{Matriz de correlação}

Figura 8 - Matriz de Correlação Brasil (2002-2015)

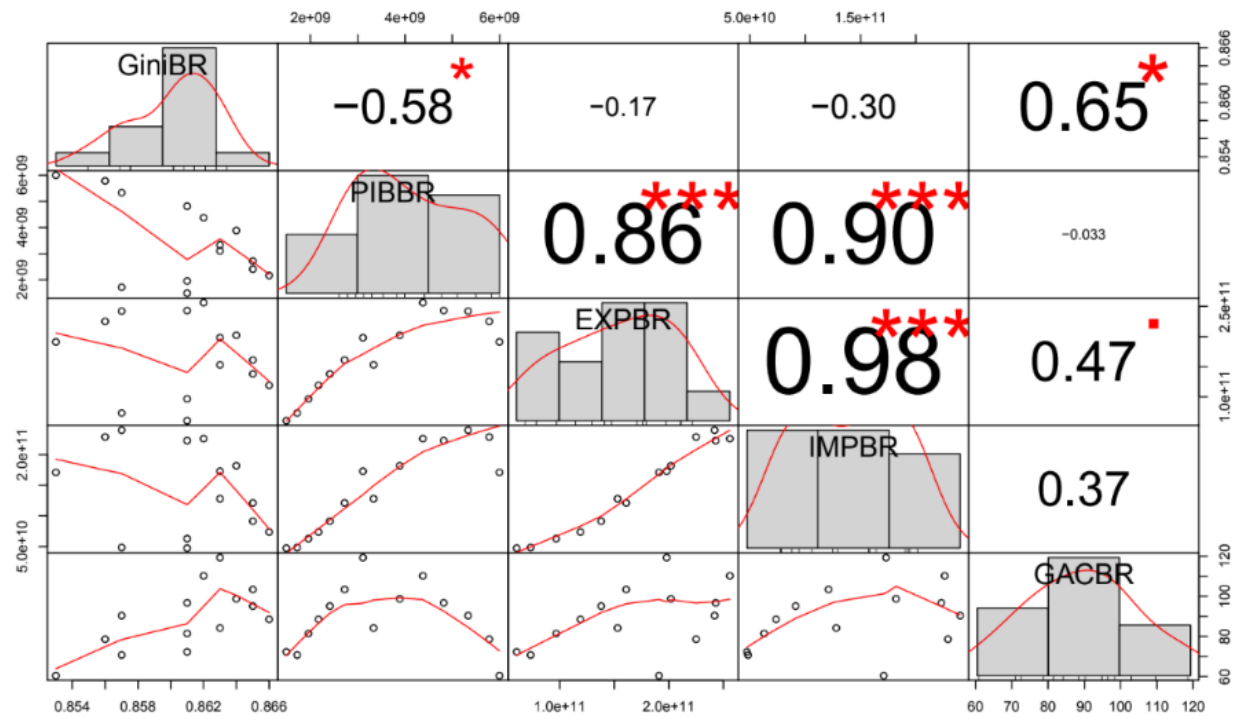

Fonte: Sidra-IBGE.

Os dados do Brasil mostram uma alta correlação positiva entre os índices PIB e Exportação em 0,86, PIB - Importação em 0,90, Exportação - Importação em 0,98, Índice de Gini - PIB de-0,58, Índice de Gini - GAC de 0,65 , sendo esses os mais significantes, o que nos mostra uma leve indicação para a redução de desigualdade e o aumento do PIB; em relação ao GAC, é ao contrário: ocorre um aumento da desigualdade com o aumento 
do GAC. Entre os índices PIB, Exportação e Importação, há uma correlação positiva muito significante.

Figura 9 - Matriz de Correlação Goiás (2002-2015)

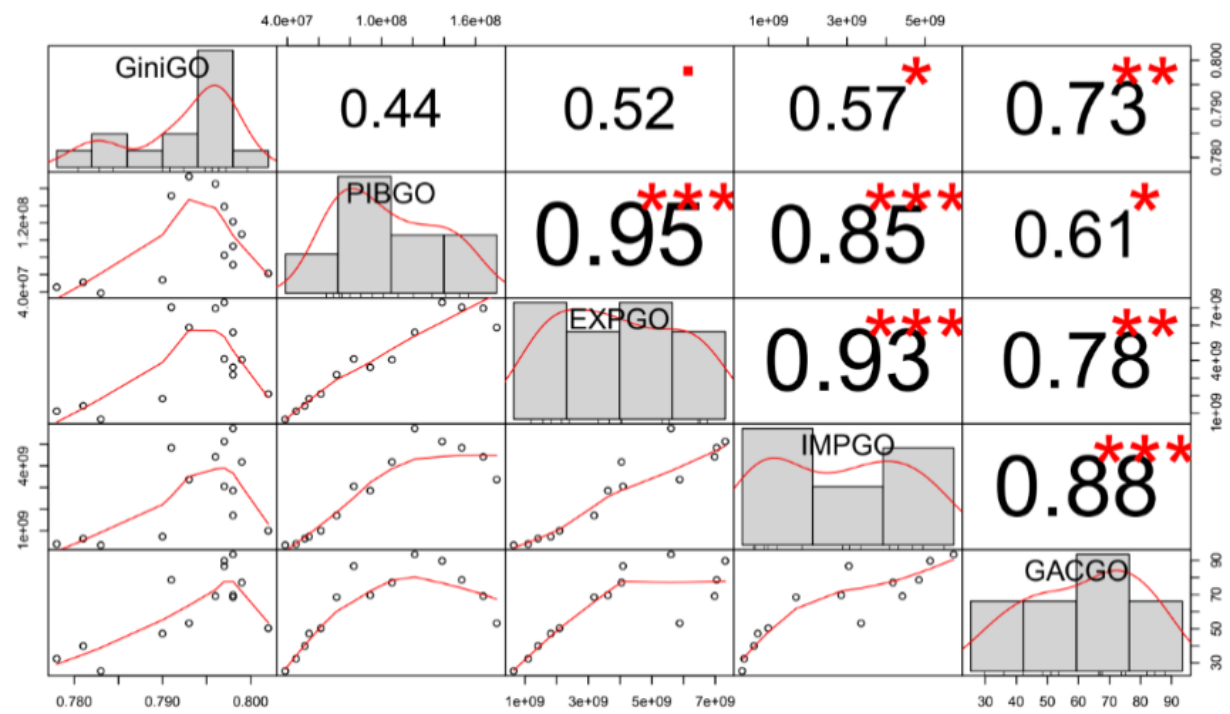

Fonte: Sidra-IBGE.

No estado de Goiás, os índices mais significantes são PIB - Exportação de 0,95, Exportação - Importação de 0,93, Importação - GAC de 0,88, PIB Importação de 0,85, Exportação - GAC de 0,78, Índice de Gini - GAC de 0,73. 
Figura 10 - Matriz de Correlação MS (2002-2015)

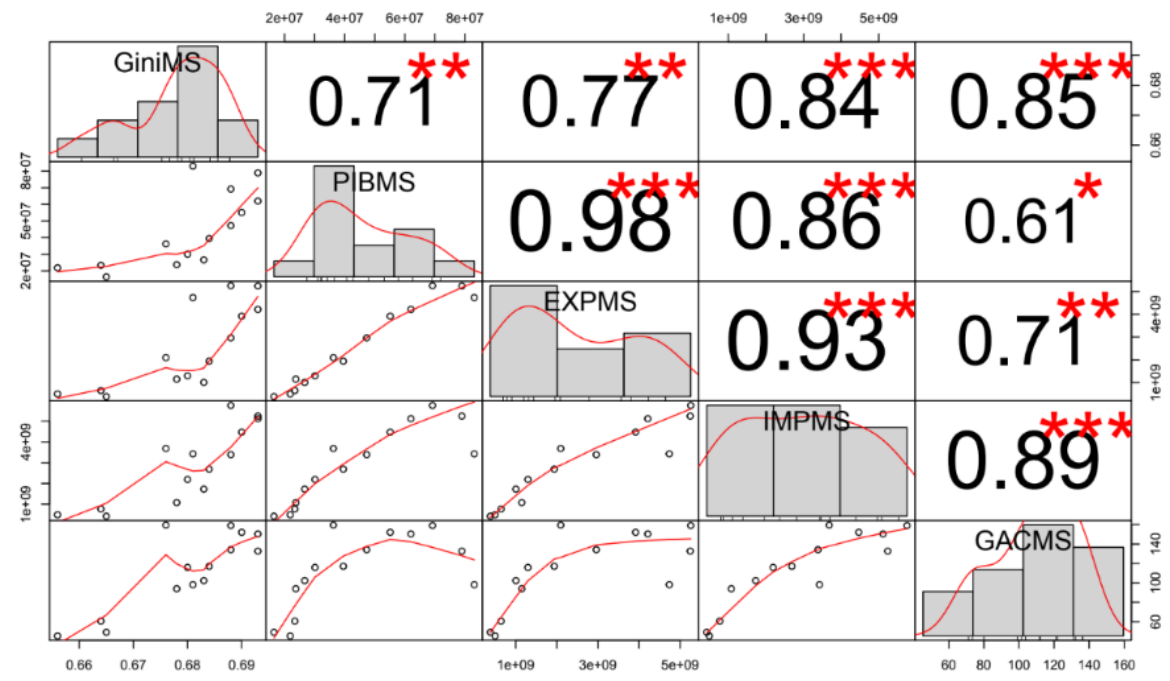

Fonte: Sidra-IBGE.

Em Mato Grosso do Sul, PIB - Exportação de 0,98, Exportação Importação de 0,93, Importação - GAC de 0,89, PIB - Importação de 0,86, Índice de Gini com GAC 0,85 e Índice de Gini com Importação de 0,84 nos mostram sempre correlação alta positiva entre as variáveis.

Figura 11 - Matriz de Correlação MT (2002-2015)

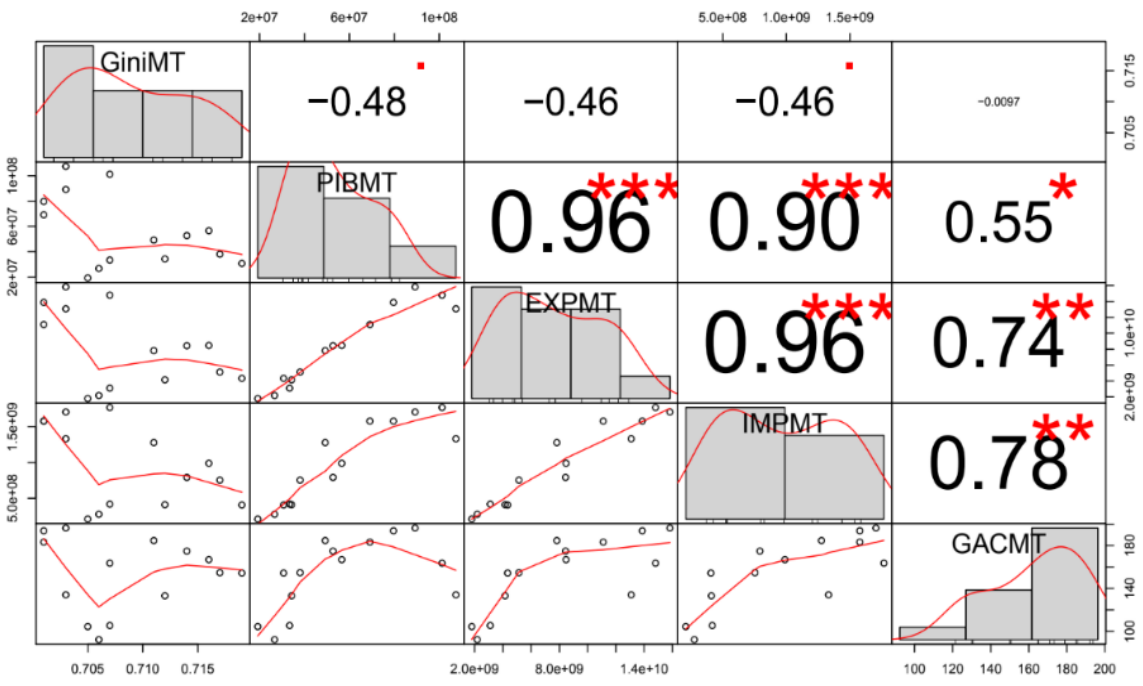

Fonte: Sidra-IBGE. 
No estado de Mato Grosso, os destaques são PIB com Exportação de 0,96, PIB com Importação de 0,90, Exportação com Importação de 0,96, com o GAC impactando positivamente as exportações e importações, e o Índice de Gini com relação negativa com as variáveis PIB, Exportação e Importação.

\section{CONSIDERAÇÕES FINAIS}

O objetivo da pesquisa foi investigar o desempenho da economia da região Centro-Oeste entre 2002-2015 e compará-lo com a média nacional usando os indicadores Produto Interno Bruto (PIB), Índice de Gini (Gini), Exportação, Importação e Grau de Abertura Comercial (GAC). O Índice de Gini (desigualdade de renda) apontou que os estados de Mato Grosso e Mato Grosso do Sul estavam com índices acima da média nacional.

No Produto Interno Bruto, os estados mostraram índices praticamente idênticos aos nacionais. No Índice de Exportação, os estados da região apresentaram índices superiores aos nacionais, com destaque para Mato Grosso do Sul e Goiás. Na Importação, apenas Mato Grosso do Sul teve índice mais alto que o nacional, Goiás e Mato Grosso tiveram os referidos índices inferiores. No Grau de Abertura Comercial, os índices foram equiparados em Goiás e Mato Grosso do Sul, apresentando índice superior ao nacional, deixando apenas Mato Grosso com índice inferior ao do Brasil.

A matriz de correlação foi o passo seguinte, em que se realizou a relação entre as variáveis e foi indicado que PIB, Exportação e Importação são diretamente proporcionais entre si, ou seja, onde um aumenta, o outro aumenta.

Quanto à desigualdade de renda em relação ao PIB, a relação é inversa no Brasil e em Mato Grosso, ou seja, aumentando o PIB, diminui a desigualdade; já em Goiás e Mato Grosso do Sul a relação foi contrária, ou seja, o aumento do PIB gerou maior desigualdade de renda, com mais impacto em MS.

O Grau de Abertura Comercial mostrou relação diretamente proporcional com todas as variáveis estudadas, ou seja, um maior grau de abertura comercial pode possibilitar um aumento das outras variáveis. 


\section{REFERÊNCIAS}

BANCO MUNDIAL. Relatório sobre o Desenvolvimento Mundial: combate à pobreza 2000/2001. Washington, D.C.: Banco Mundial, 2001. Disponível em: https://documents.worldbank.org/pt/publication/documents-reports/ documentdetail/927161468164645652/relatorio-sobre-o-desenvolvimentomundial-2000-2001-luta-contra-a-pobreza. Acesso em: 13 set. 2019.

BARROS, A. R. Desigualdades regionais no Brasil: natureza, causas, origens e soluções. Rio de Janeiro: Elsevier, 2011.

CACCIAMALI, M. C.; CAMILLO, V. S.. Redução da desigualdade da distribuição de renda entre 2001 e 2006 nas macrorregiões brasileiras: tendência ou fenômeno transitório. A construção da igualdade de gênero e raça na América Latina do século XXI: o caso do Brasil. São Carlos: Suprema, 2008.

CANUTO, O.; FLEISCHHAKER, C.; SCHELLEKENS, P. O curioso caso da falta de abertura do Brasil ao comércio. Revista Brasileira de Comércio Exterior, n. 122, p. 20-25, 2015. CASS, D. Studies in the Theory of Optimum Economic Growth. Tese (Doutorado em Economia) - Stanford University, 1965.

CAVALCANTE, L. R.; DE NEGRI, F. Produtividade no Brasil: uma análise do período recente. Texto para Discussão. Instituto de Pesquisa Econômica Aplicada (Ipea), 2014.

CONSTANTINO, M.; PEGORARE, A. B.; COSTA, R. B. Desempenho regional do IDH e do PIB per capita dos municípios de Mato Grosso do Sul, Brasil, entre 2000 e 2010. Interações, Campo Grande, MS, v. 17, n. 2, p. 234-46, abr./jun. 2016.

CORRÊA, A. M. C. J.; DE FIGUEIREDO, N. M. S. Riqueza, desigualdade e pobreza: um perfil da Região Centro-Oeste no início do séc. XXI. Pesquisa \& Debate, v. 17, n. 1 (29), 2006.

DINIZ, B. P. C. O grande cerrado do Brasil central: geopolítica e economia. 2006. 231f. Tese (Doutorado em Geografia) - Universidade de São Paulo, São Paulo, SP, 2006.

GRASEL, D.; VIEIRA, E. A.; MENDES, M. P.; BERCHIELI, R. Desigualdade, pobreza e crescimento: uma análise comparativa entre Mato Grosso e Santa Catarina. Textos de Economia, Florianópolis, v. 11, n. 1, p. 54-78, 2008. 
FAGUNDES, M. B. B. (Coord.). Relatório de pesquisa: elaboração da TRU (Tabela de Recursos e Usos) e construção da matriz insumo-produto 2008. Campo Grande: UFMS, jan. 2013.

GUILHOTO, J.; ICHIHARA, S. M.; SILVEIRA, F. G.; DINIZ, B. P. C.; AZZONI, C. R.; MOREIRA, G. R. C. A importância da agricultura familiar no Brasil e em seus estados (Family agriculture's gdp in Brazil and in it's states). In: ENCONTRO NACIONAL DA ASSOCIAÇÃO BRASILEIRA DE ESTUDOS REGIONAIS E URBANOS, 5., 2007, São Paulo. Anais [...]. São Paulo: Anpec, 2007.

INSTITUTO DE PESQUISA APLICADA. Desafios do Desenvolvimento, Brasília-DF, ano 1, 2004.

INSTITUTO DE PESQUISA E ESTRATÉGIA ECONÔMICA DO CEARÁ. Entendendo o Índice de Gini. Fortaleza: Governo do Estado do Ceará/Ipece, 2010.

ROSSI JUNIOR, J. L.z; FERREIRA, P. C. Evolução da produtividade industrial brasileira e abertura comercial. Rio de Janeiro: Ipea, 1999.

KAWAMOTO, C. T.; SANTANA, B. L.; FONSECA, H. Elasticidade renda e elasticidade preço das exportações e das importações de produtos industrializados no Brasil (2003-2010): uma avaliação utilizando dados em painel. Revista de Economia, v. 39, n. 2 (ano 37), p. 139-59, maio/ago. 2013.

KOOPMANS, T. C. On the concept of optimal economic growth. In: Study Week on the Econometric Approach to Development Planning. Rome: Pontifical Academy of Science, 1965.

KRUGMAN, P. R.; OBSTFELD, M. Economia internacional: teoria e política. 8. ed. São Paulo: Pearson Addison Wesley, 2010.

MAGALHÃES, J. C. R.; BOUERI, R. M. Dinâmica da renda per capita, longevidade e educação nos municípios brasileiros. Estudos econômicos, v. 39, n. 3, p. 539-69, 2009.

MANKIW, N. Gregory. Introdução à economia, princípios de micro e macroeconomia. Editora Campos, 2005.

MARQUES, A. M. Crescimento econômico e grau de desigualdade no Rio Grande do Sul: uma lição a partir dos anos noventa. Estudos do Cepe, n. 30, p. 6-29, 2009. 
NEDER, H. D. Análise de indicadores sociais utilizando o Stata, Instituto de Economia, 2013. Disponível em: http://www.ecn26.ie.ufu.br/TEXTOS_ESTATISTICA/ANALISE_ POLITICAS_SOCIAIS.pdf. Acesso em: 13 set. 2019.

RAMSEY, F. P. A. Mathematical theory of saving. The Economic Journal, n. 38, p. 543-59, 1928.

RESENDE, G. M.; MAGALHÃES, J. C. R. Disparidades do produto interno bruto (PIB) per capita no Brasil: uma análise de convergência em diferentes escalas regionais (1970-2008). Repositório do Conhecimento do Ipea, Brasília, 2013. [Texto para discussão, 1833].

SANTOS, A. M.; SOUSA, E. A.; TEJADA, C. A.; JACINTO, P. A. Elasticidades preço e renda das exportações e importações: uma abordagem através de dados de painel para os estados do Brasil. In: ENCONTRO NACIONAL DA ASSOCIAÇÃO BRASILEIRA DE ESTUDOS REGIONAIS E URBANOS (ENABER), 7., 2009.

SILVA, A. C.; LIMA, E. P. C.; BATISTA, H. R. A importância da soja para o agronegócio brasileiro: uma análise sob o enfoque da produção, emprego e exportação. Criciúma: Apec, 2012.

SOLOW, R. M. A contribution to the theory of economic growth. The Quarterly Journal of Economics, v. 70, n. 1, p. 65-94, 1956.

SHANKAR, R.; SHAH, A. Bridging the economic divide within countries: A scorecard on the performance of regional policies in reducing regional income disparities. World development, v. 31, n. 8, p. 1421-41, 2003.

SWAN, T. Economic growth and capital accumulation. Economic Record, v. 32, n. 2, p. 34-361, nov. 1956.

THE HERITAGE FOUNDATION. Washington DC, 2020. Disponível em: https://www. heritage.org/. Acesso em: 13 set. 2019.

TREMEA, N. J. C. As exportações e o produto interno bruto do Brasil no período de 2000 a 2009. Revista ADM Gestão Estratégica, v. 4, n. 1, 2011. 